\title{
Exploring the Mechanical, Thermal and Ballistic Effects of Carbon Black on Paraffin-Based Fuels for Hybrid Rocket Motors
}

Paula Cristina Gomes Fernandes, Jessica Santos Gomes², Elizabete Yoshie Kawachi , Marcio Yuji Nagamachi², Luiz Fernando de Araujo Ferrão", Kamila Pereira Cardoso2,*

\author{
Fernandes PCG (1D https: / / orcid. org/0000-0003-2058-3699 \\ Gomes JS (1) https: / / orcid.org/0000-0001-8152-9034 \\ Kawachi EY (D) https://orcid.org/0000-0002-6477-0886 \\ Nagamachi MY (D) https: / /orcid.org/0000-0001-7617-8647 \\ Ferrão LFA (1D https://orcid.org/0000-0003-1294-8707 \\ Cardoso KP (D) https://orcid.org/0000-0001-5308-0188
}

\section{How to cite}

Fernandes PCG; Gomes JS; Kawachi EY; Nagamachi MY; Ferrão LFA; Cardoso KP (2019) Exploring the Mechanical, Thermal and Ballistic Effects of Carbon Black on Paraffin-Based Fuels for Hybrid Rocket Motors. J Aerosp Technol Manag, 11, Special Edition: 19-22. https://doi.org/10.5028/jatm. etmq.64

\begin{abstract}
Paraffin-based hybrid propellants have been developed due to their high burning rate. However, they have some disadvantages such as inadequate mechanical properties and unstable burning. In this work, paraffin fuel grains with carbon black were evaluated to study the possible effects of this additive on the mechanical, thermal and ballistic properties of these grains, besides the already known effect of minimizing the thermal radiation inside the motor. The grains with carbon black showed significant changes in the thermal degradation profile and substantial improvement in burn stability.
\end{abstract}

KEYWORDS: Hybrid propellant; Paraffins; Burning rate; Propellant additives.

\section{INTRODUCTION}

Hybrid propulsion has been receiving increasing interest because it is a technically, economically and safety advantageous alternative when compared to liquid or solid propellants (Karabeyoglu et al. 2002). In typical hybrid rocket motors, the liquid oxidizer is contained in a pressurized tank and is injected into a chamber containing the solid fuel, which is in the form of a molded grain. Thrust can be controlled by adjusting the oxidizer flow and can operate with multiple reignition during the flight (Karabeyoglu et al. 2004).

Among the fuels used in hybrid propulsion, paraffin has been evaluated due to its high burning rate. The solid paraffin block melts in contact with the oxidizer at high pressure and temperature, forming a thin layer of liquid that disperses in small drops. This improves the mixing conditions between fuel and oxidizer, bringing the burning conditions closer to those of a liquid propellant (Karabeyoglu et al. 2004). Although it has the advantages already mentioned, a major obstacle to its use as a fuel grain is its mechanical property: solid paraffin is very fragile, which increases the risk of cracking and making its use unfeasible. Also, its low melting point can cause excessive grain liquefaction during burning. To minimize this last factor, it is common to add carbon black to paraffin to reduce the thermal radiation inside the motor (Karabeyoglu et al. 2004; George et al. 2001).

1.Departamento de Ciências e Tecnologia Aeroespacial - Instituto Tecnológico de Aeronáutica - Departamento de Química - São José dos Campos/SP - Brazil

2.Departamento de Ciências e Tecnologia Aeroespacial - Instituto de Aeronáutica e Espaço - Divisão de Propulsão - São José dos Campos/SP - Brazil

*Correspondence author: cardoso.kp@gmail.com

Received: 27 Nov 2019 | Accepted: 10 Dec 2019

Note: This paper was selected from the 10 Encontro Técnico de Materiais e Química (ETMQ) ocurred in 27-29 november of 2019 and organized by Instituto de Pesquisas da Marinha (IPqM) in Rio de Janeiro/RJ, Brazil 
The main objective of this work is to explore the influence of carbon black on other characteristics within a paraffin fuel grain. In particular, by evaluating whether the physicochemical interactions of paraffin with carbon black (paraffin/ $\mathrm{CB}$ ) influence its mechanical properties and the combustion process of this material. For this, besides burning tests, stressstrain mechanical analyses were carried out, as well as a thermogravimetric analysis coupled with a kinetic treatment.

\section{MATERIALS AND METHODS}

The following materials were used for the processing of fuel grains: paraffin wax 170/190 (Petrobras - 0314497) and carbon black (Columbian - ST300). The pure paraffin wax fuel grain was prepared by heating at $80{ }^{\circ} \mathrm{C}$ until complete melting, then the liquid was quickly poured into the rocket motor case (with a star-shaped mold), which was previously heated. The temperature was slowly decreased to avoid imperfections and eventual grain shrinkage during cooling. For the preparation of paraffin/CB fuel grain, after melting the paraffin, 5 wt.\% of carbon black was added with the aid of a mechanical stirrer and the process followed the same molding procedure as the pure paraffin.

The mechanical properties were obtained in an optical extensometer of ZWICK 1474, according to the STANAG 4506 (NATO 2000). The thermal degradation profile of the samples was analyzed by thermogravimetry (TA instrument model SDTQ600). The samples were exposed to an oxidizing atmosphere with a flow rate of $100 \mathrm{~mL} \cdot \mathrm{min}^{-1}$ and a heating rate of 5,10 and $15 \mathrm{~K} \cdot \mathrm{min}^{-1}$. Kinetic parameters were obtained according to ASTM E1641-13 (2013) based on the Flynn and Wall method (Flynn and Wall 1966). The firing test was performed with an oxygen flow of $320 \mathrm{~g} \cdot \mathrm{s}^{-1}$ and the internal pressure was obtained by a pressure transducer (Honeywell model Z).

\section{RESULTS AND DISCUSSION}

The incorporation of carbon black in paraffin grain did not lead to qualitative changes in its mechanical properties, as expected, because these components only have physical interactions. However, paraffin/CB samples had an increase in maximum stress (1.6 MPa) and rupture elongation (0.45\%) when compared to the values of pure paraffin wax (0.5 MPa and $0.25 \%)$. Despite the improvement in elasticity and strength, both grains do not have adequate mechanical properties for this application, where the optimum rupture strain is in the range of 30 to $65 \%$.

On the other hand, carbon black has a crucial effect on the thermal degradation profile and possibly on the combustion mechanism of paraffin. Figure 1a shows the thermogravimetric analysis of paraffin and paraffin/CB samples. The two main events of paraffin thermal degradation can be observed in both samples. The first one occurred in the range of 200 to $350^{\circ} \mathrm{C}$ and is related to the decomposition of low molar mass chains, leading to a mass loss of approximately $80 \%$. The second event, responsible for the loss of the remaining $20 \%$ of the mass, occurred between 380 and $500{ }^{\circ} \mathrm{C}$ and refers to the decomposition of carbon chains with high molar mass.

At the lower heating rate $\left(5^{\circ} \mathrm{C} \cdot \mathrm{min}^{-1}\right)$, the addition of carbon black decreases the paraffin thermal stability, facilitating its degradation at lower temperatures, while at higher heating rates there is a shift of the degradation events to slightly higher temperatures. In short, this behavior leads to a drastic $(\sim 50 \%)$ decrease in activation energy in carbon black samples. Figure $1 \mathrm{~b}$ shows the activation energy in both samples as a function of the converted mass. It is noteworthy that the conditions of this analysis do not express the real operational conditions on the rocket motor. However, these results suggest that the interaction between these components may influence the thermal degradation and combustion of paraffin. Preliminary firing tests showed more stable combustion in carbon black-containing grains than those of pure paraffin wax.

Figure 2a shows the fuel grains before and after the test, while Fig. $2 \mathrm{~b}$ shows the combustion chamber pressure curve versus time in a ballistic test for both samples. It can be observed that both had similar chamber pressure values, however, the pure 
(a)

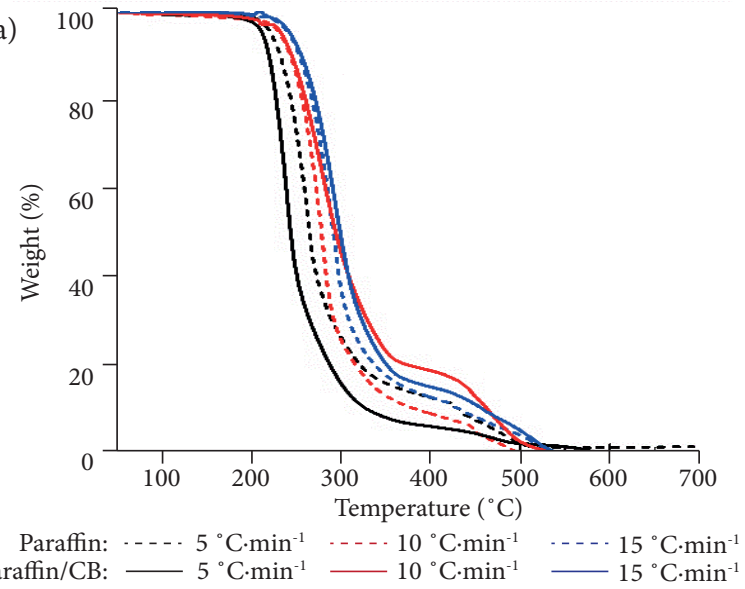

(b)

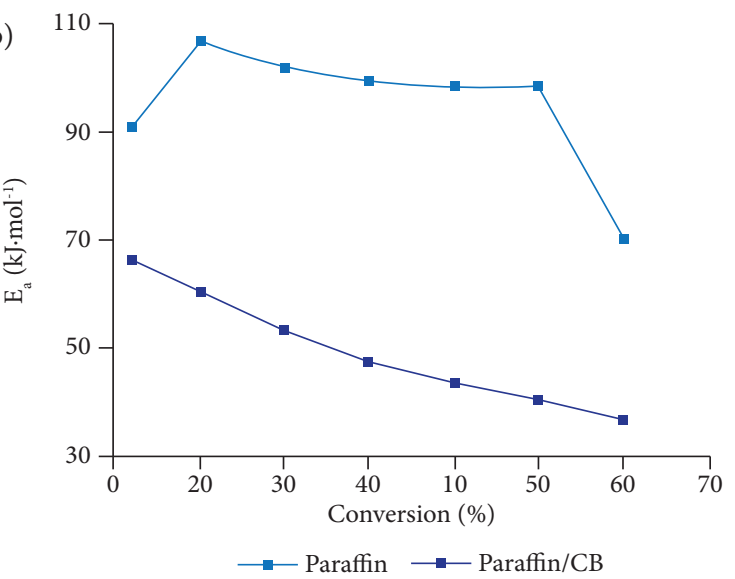

Figure 1. (a) Thermogravimetric analysis curves of paraffin and paraffin/CB samples for various heating rates. (b) Activation energy on thermal decomposition of paraffin and paraffin/CB samples as a function of the mass loss percentage (conversion).

(a)

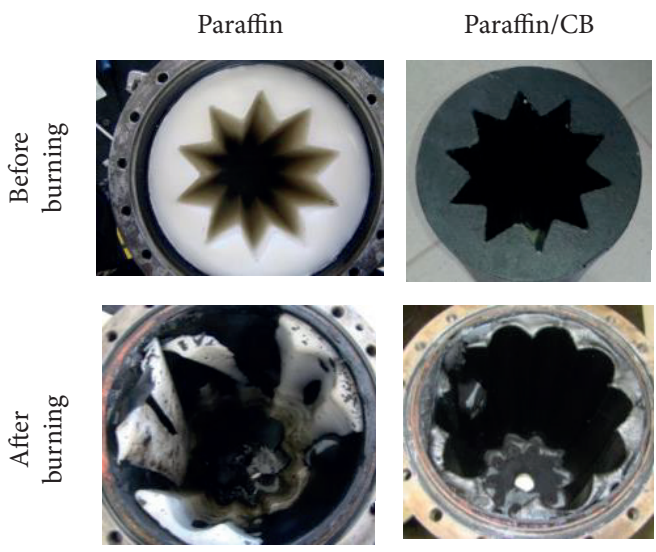

(b)

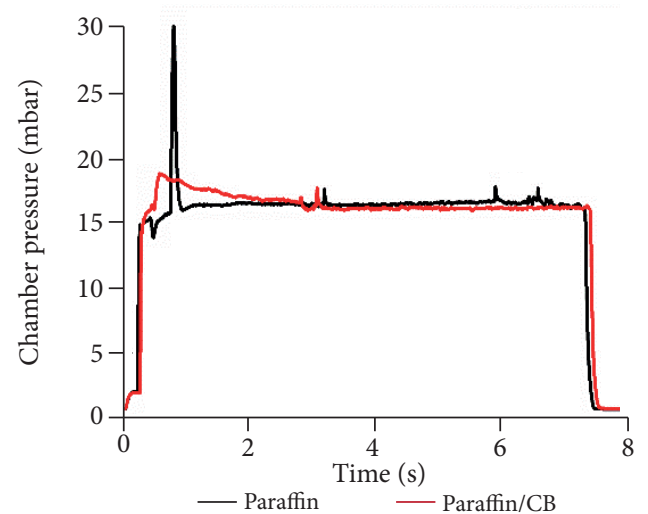

Figure 2. (a) Paraffin and paraffin/CB fuel grains before and after the burning test; (b) Combustion chamber pressure of the samples during the burning test.

paraffin grain presented instability during burning, with a pressure peak in the initial moments. On the other hand, the carbon black grain showed significantly higher stability without any abrupt increase of pressure.

When comparing the thermogravimetric results with those from the burning tests, it can be assumed that the additive has some concomitant effects: it lowers the transference of thermal energy, changes the degradation mechanism of the fuel and increase the viscosity and surface tension of the melting layer. This last factor increases the stability of the liquefied film and, therefore, moderates the dispersion of the drops in the reaction zone.

\section{CONCLUSION}

In this work, it was possible to verify the influence of carbon black on paraffin fuel grains. There were improvements in the mechanical properties, but not enough for aerospace applications. However, there was a significant change in the thermal degradation profile and, mainly, in the firing stability when incorporating this additive. These results suggest that carbon black can act as a multifunction additive. 


\section{ACKNOWLEDGMENTS}

The authors acknowledge the technicians and researchers of IAE for the support and friendship.

\section{FUNDING}

Fundação de Amparo à Pesquisa do Estado de São Paulo [http://doi.org/10.13039/501100001807]

Grants (2019/03042-2 and 2019/03729-8)

Conselho Nacional de Desenvolvimento Científico e Tecnológico [http://doi.org/10.13039/501100003593]

Grants (381544/2018-4, 309051/2016-9, 157662/2018-7 and 406107/2016-5)

Coordenação de Aperfeiçoamento de Pessoal de Nível Superior [http://doi.org/10.13039/501100002322]

Grant (88887.142345/2017-00)

\section{AUTHOR'S CONTRIBUTION}

Conceptualization, Ferrão LFA and Cardoso KP; Methodology, Nagamachi MY, Ferrão LFA and Cardoso KP; Research, Fernandes PCG and Gomes JS; Writing - First version, Fernandes PCG and Gomes JS; Writing - Review \& Editing, Kawachi EY, Cardoso KP and Ferrão LFA; Acquisition of Funding, Kawachi EY, Cardoso KP and Ferrão LFA; Resources, Nagamachi MY; Supervision, Kawachi EY, Nagamachi MY, Cardoso KP and Ferrão LFA.

\section{REFERENCES}

[ASTM] American Society for Testing and Materials (2013) Standard Test Method for Decomposition Kinetics by Thermogravimetry Using the Ozawa/Flynn/Wall Method - ASTM E1641-13. West Conshohocken (Pennsylvania): ASTM International. https://doi.org/10.1520/E1641-13

[NATO] North Atlantic Treaty Organization (2000) STANAG 4506 - Explosive materials, physical/mechanical properties uniaxial tensile test. Brussels (Belgium): NATO.

Flynn JH, Wall LA (1966) A quick, direct method for the determination of activation energy from thermogravimetric data. J Polym Sci Part B Polym Lett 4(5):323-328. https://doi.org/10.1002/pol.1966.110040504

Flynn JH, Wall LA (1966) General Treatment of the Thermogravimetry of Polymers. J Res Natl Bur Stand - A Phys Chem 70(6):487-523. https: / / doi.org/10.6028/jres.070A.043

George P, Krishnan S, Varkey PM, Ravindran M, Ramachandran L (2001) Fuel regression Rate in Hydroxyl-Terminated-Polybutadiene/GaseousOxygen Hybrid Rocket Motors. J Propul Power 17(1):35-42. https://doi.org/10.2514/2.5704

Karabeyoglu MA, Altman D, Cantwell BJ (2002) Combustion of Liquefying Hybrid Propellants: Part 1, General Theory. J Propul Power 18(3):610620. https://doi.org/10.2514/2.5975

Karabeyoglu MA, Altman D, Cantwell BJ, inventors (2004a). High Regression Rate Hybrid Rocket Propellants. United States patent US 6,684,624B2.

Karabeyoglu MA, Zilliac G, Cantwell BJ, DeZilwa S, Castellucci P (2004b) Scale-up Tests of High Regression Rate Paraffin-Based Hybrid Rocket Fuels. J Propul Power 2O(6):1037-1045. https://doi.org/10.2514/1.3340 